BULLETIN Bulletin hispanique

HISPANIQUE Université Michel de Montaigne Bordeaux

$120-2$ | 2018

Varia

\title{
Abecedarios de devoción: lulismo, cábala y arte de la memoria en Puerta de la luz de Agustín Núñez Delgadillo
}

Abécédaires de dévotion : lullisme, Kabbale et art de la mémoire dans

Puerta de la luz de Agustín Núñez Delgadillo

Devotion alphabet primers: Lullism, Kabbalah, and the art of memory in

the "Puerta de la Luz" by Agustín Núñez Delgadillo

Rafael Ramis-Barceló y Anna Serra Zamora

(2) OpenEdition

Journals

Edición electrónica

URL: https://journals.openedition.org/bulletinhispanique/6387

DOI: 10.4000/bulletinhispanique.6387

ISSN: $1775-3821$

Editor

Presses universitaires de Bordeaux

Edición impresa

Fecha de publicación: 10 diciembre 2018

Paginación: 397-418

ISBN: 979-10-300-0337-6

ISSN: 0007-4640

Referencia electrónica

Rafael Ramis-Barceló y Anna Serra Zamora, «Abecedarios de devoción: lulismo, cábala y arte de la memoria en Puerta de la luz de Agustín Núñez Delgadillo», Bulletin hispanique [En línea], 120-2 | 2018, Publicado el 02 enero 2022, consultado el 07 enero 2022. URL: http://journals.openedition.org/ bulletinhispanique/6387 ; DOI: https://doi.org/10.4000/bulletinhispanique.6387 


\title{
Abecedarios de devoción: lulismo, cábala y arte de la memoria en Puerta de la luz de Agustín Núnez Delgadillo
}

\author{
Rafael Ramis-Barceló, Anna Serra Zamora \\ Universitat de les Illes Balears, Universitat Pompeu Fabra
}

Abécédaires de dévotion : lullisme, Kabbale et art de la mémoire dans Puerta de la luz de Agustin Núñez Delgadillo

Cet article analyse le livre Puerta de la luz (1629), du carmélite Augustin Núñez Delgadillo (1570-1631), du point de vue de son contenu religieux, lulliste et kabbaliste. À la contextualisation et à l'analyse de l'œuvre s'ajoute l'exposition de huit alphabets avec leurs combinaisons, litanies et déprécations, dans le cadre de la pédagogie des Carmes, profondément influencée par Lulle et les méthodes mnémotechniques de la rhétorique baroque.

Mots clés: Agustín Núñez Delgadillo, abécédaire, lullisme, kabbale, dévotion.

Este artículo analiza el libro Puerta de la luz (1629), del carmelita Agustín Núñez Delgadillo (1570-1631) desde el punto de vista de su contenido religioso, lulista y cabalista. Se presenta una contextualización y un análisis de la obra, con la exposición de ocho abecedarios, sus combinaciones, letanías y deprecaciones correspondientes, en el marco de la pedagogía carmelitana con un profundo influjo de los métodos lulianos y de la mnemotécnica de la retórica barroca.

Palabras clave: Agustín Núñez Delgadillo, abecedario, lulismo, cábala, devoción.

Devotion alphabet primers: Lullism, Kabbalah, and the art of memory in the "Puerta de la Luz" by Agustin Núñez Delgadillo

This paper analyses the book "Puerta de la luz"(1629), by the Carmelite Agustín Núnez Delgadillo (1570-1631) from the point of view of its religious, Lullist and Kabbalist content. We present a contextualization and analysis of the work, with the exposition of eight alphabets, their combinations, litanies and deprecations, within the frame of Carmelite pedagogy, a deep influence of Lullian methods and mnemotechnic of the baroque Rhetoric.

Keywords: Agustín Núñez Delgadillo, Alphabet, Lullism, Kabbalah, devotion. 
Pues asi decimos de nuestro $A B C$, está todo Dios en cada letra. Agustín Núñez Delgadillo, Puerta de la luz, II, 5

$\mathrm{E}$ n las páginas siguientes nos proponemos dar a conocer una de las obras más curiosas del barroco hispánico, considerada perdida hasta hace poco: Puerta de la luz de Agustín Núñez Delgadillo. Más allá de la relevancia de la recuperación de este escrito perseguido por la Inquisición, pretendemos destacar los rasgos más sobresalientes del libro, una singular síntesis en lengua castellana de lulismo, cábala y arte de la memoria en el contexto de la literatura religiosa y retórica del primer tercio del siglo XVII.

El objetivo de nuestra investigación es mostrar las novedades que presenta esta obra en el marco de la literatura del barroco hispano. Destacaremos tres puntos de partida: 1) se trata una obra de gran audacia en la composición, pues representa la cúspide creativa de su autor, un notable profesor y predicador carmelita; 2) en ella se dan la mano la predicación, el arte de la memoria y el lulismo, en un tratado sintético con influencias del mundo carmelitano, de la mística y de la cábala; 3) por su audacia, esta obra resultó un peligro para los inquisidores: leída en la actualidad resulta más transgresora que el Fenix de Minerva y otras obras coetáneas sobre el arte de la memoria.

\section{INTRODUCCIÓN: EL AUTOR Y EL CONTEXTO DE LA OBRA}

Aunque se dio por perdida ${ }^{1}$ durante mucho tiempo a pesar de sus dos ediciones (Madrid, 1629²; Zaragoza, 1630³), y gracias a nuestras indagaciones en el catálogo de la Biblioteca del Monasterio de las Reales Descalzas de Madrid, pudimos tener acceso a un ejemplar de Puerta de la luz $z^{4}$. A través de la exposición de ocho abecedarios, sus combinaciones, letanías y deprecaciones correspondientes, puede verse su curiosa síntesis de elementos procedentes de la

1. F. Domínguez Reboiras, «Estudio Preliminar», Raimundi Lulli Opera Latina (ROL) XVIII, 1991, Turnhout, Brepols, p. 33.

2. Puerta de la Luz, para conocer y tener presentes en todas las acciones, palabras y pensamientos á Dios..., a Iesu Christo... á la Virgen soberana y grauedad del pecado por las letras del ABC, Madrid, Juan Gonçalez, 1629.

3. Puerta de la Luz, para conocer y tener presentes en todas las acciones, palabras y pensamientos a Dios nuestro Señor, a Jesucristo, nuestro salvador, su sagrada pasión... á la Virgen soberana y grauedad del pecado por las letras del Abecedario, Zaragoza, Pedro Vergés, 1630.

4. Real Monasterio de las Descalzas, sign. MD/G/101. 
espiritualidad carmelitana, los métodos lulianos, cabalistas y mnemotécnicos. La obra figuraba en distintas ediciones del Índice de libros prohibidos (1632 y $\left.1640^{5}\right)$. Antes de entrar en su análisis, cabe detenerse en el autor ${ }^{6}$.

Agustín Núñez Delgadillo (Córdoba, $1570^{7}$ - Madrid, 1631) fue uno de los predicadores más destacados del siglo $\mathrm{XVII}^{8}$. En 1586 hizo profesión como carmelita observante en el Convento de Nuestra Señora de la Cabeza de Granada. Obtuvo los grados de Bachiller, Licenciado y Maestro (1593) en la Facultad de Artes de la Universidad de Osuna ${ }^{9}$, donde enseńó Artes ${ }^{10}$. Empezó los estudios teológicos en el Colegio de San Alberto de Sevilla ${ }^{11}$ y según indica Martínez Carretero, alcanzó el doctorado en Teología en Roma ${ }^{12}$, cuando allí se debatía la causa de Llull ${ }^{13}$. En la última etapa de su vida predicó en la Corte. De hecho, la dedicatoria de Puerta de la luz, a la Infanta Sor Margarita de la Cruz, por un lado, muestra los vínculos del carmelita con la Corte (firma la dedicatoria como "Capellán de V. A.») y, por el otro, nos ayuda a comprender por qué se conservó un ejemplar en el Monasterio de las Descalzas Reales, puesto que Sor Margarita (1567-1633), hija de Maximiliano II de Habsburgo, había ingresado en ese convento de clarisas.

Según Gonzalo Díaz, Núñez Delgadillo «profesó las doctrinas lulistas, que trató de difundir a través de su labor de cátedra, consiguiendo incluso durante su paso por la Universidad de Zaragoza que se proveyera una cátedra de lulismo» ${ }^{14}$. El P. M. Garrido, en cambio, siguiendo la opinión de Nicolás Antonio $^{15}$ sostiene que la Universidad instituyó una cátedra ad personam ${ }^{16}$, y

5. Index librorum prohibitorum et expurgandorum novissimus, Madrid, ex typographaeo Didaci Diaz, 1640, p. lxvi.

6. Acerca del autor y sus datos bio-bibliográficos véase: Rafael Ramis Barceló y Anna Serra Zamora, "La censura inquisitorial de Puerta de la Luz de Fray Agustín Núńez Delgadillo», Revista de la Inquisición (Intolerancia y Derechos humanos), Vol. 18, 2014, pp. 81-93.

7. O. Barea López, Heráldica y genealogía de Cabra de Córdoba, Doña Mencía y Monturque y de sus enlaces (ss. XV-XIX), II, Bubok Publishing, 2012, p. 52.

8. Abundantes elogios sobre su vida, escritos poco tiempo después de su fallecimiento, pueden verse en la clásica obra de M. A. Alegre de Casanate, Paradisus Carmelitici decoris, Lugduni, Iacobi \& Petri Prost, 1639, pp. 498-500.

9. F. Rodríguez Marín, Apuntes y documentos para la historia de Osuna, Osuna, Imprenta de M. Ledesma Vidal, 1889, pp. 791-792.

10. Siendo allí "universalmente aclamado", según M. Rodríguez Carretero, Epitome historial de los Carmelitas de Andalucía y del Reino de Granada, Sevilla, Grafisur, 2000, p. 264.

11. Idem.

12. I. Martínez Carretero, Los Carmelitas en Sevilla. 650 años de presencia (1358-2008), Sevilla, Provincia Bética de PP. Carmelitas, 2009, pp. 273-276.

13. P. J. Sánchez de Lizárazu, Generalis et admirabilis methodus, ad omnes scientias facilius et citius addiscendas, in qua explicatur Ars brevis Raymundi Lulli..., Tyrasonæ, Per Carolum a Lauayen, 1613.

14. G. Díaz Díaz, Hombres y documentos de la filosofía española, vol. V, Madrid, CSIC, 1995, p. 842.

15. N. Antonio, Bibliotheca hispana, vol. 1, Madrid, Joaquín de Ibarra, 1783, p. 177.

16. P. M. Garrido, Santa Teresa, San Juan de la Cruz y los carmelitas españoles, Salamanca, Universidad Pontificia de Salamanca, 1982, p. 98. 
que Delgadillo aprovechó para dictar un curso sobre el Arte luliana. De hecho, su estadía en Zaragoza fue harto problemática, dado que su curso sobre el Arte de Llull fue denunciado ante la Inquisición ${ }^{17}$. Se ha dicho que desempeńó cátedras en las universidades de Córdoba, Granada, Valencia y Alcalá, un dato que parece exagerado y del cual no hay pruebas documentales ${ }^{18}$, a excepción de su paso por Granada ${ }^{19}$. A nuestro entender, más bien debían de ser lectorados conventuales de su propia orden.

El primer conflicto relevante de Núñez Delgadillo con el Santo Oficio parece ser que se produjo durante su etapa como profesor en la Universidad de Zaragoza, entre 1610 y $1612^{20}$, lapso en el cual, como se ha dicho, debió de enseñar lulismo. En 1610, los inquisidores del Tribunal de Aragón enviaron a la Suprema un expediente con las calificaciones que se habían hecho de la lectura del Arte parva et magna de Lulio ${ }^{21}$. Pese a que no se atrevieron a dictar una condena de estas doctrinas, el maestro Delgadillo acató a su Rector y no enseñó de nuevo las doctrinas del mallorquín, quien, cabe recordarlo, estaba a la sazón en proceso de beatificación y ya había recibido una protección férrea por parte de Felipe II ante la persecución de los dominicos ${ }^{22}$. Afortunadamente, entre la documentación inquisitorial, se encuentra una copia del curso $^{23}$ sobre el Arte de Llull, dictado en 1610, y que fue examinado por los calificadores.

17. R. Ramis Barceló, «El proceso de la Inquisición contra la lectura del Arte de Ramon Llull en la Universidad de Zaragoza (1610)», Hispania Sacra, vol. 66, extra I, enero-junio 2014, pp. 131-160.

18. G. Díaz Díaz, Hombres y documentos..., pp. 841-843, siguiendo a Nicolás Antonio, Bibliotheca hispana, p. 177.

19. A. Núnez Delgadillo, Sermon de la gloriosa Sancta Teresa de Iesus, predicado en el Conuento de las Carmelitas Descalças de Granada, Lunes de su octaua. "Por el Padre Maestro Fray Augustin Nuńez Delgadillo, Carmelita Lector de prima de Theologia, y Regente de los estudios en el Conuento de Nra. Señora de la Cabeça de la mesma Ciudad», Granada, imprenta de Juan Muñoz, 1617.

20. Véase R. Ramis Barceló, «El proceso de la Inquisición contra la lectura del Arte de Ramon Llull en la Universidad de Zaragoza (1610)», pp. 145-150.

21. AHN (= Archivo Histórico Nacional), Consejo de la Inquisición, L. 970, f. 433 (antigua numeración, f. 425). Uno de los inquisidores era Fr. Miguel Santos de San Pedro, inquisidor de Aragón de 1604 a 1621. Véase A. Sarrión, Médicos e inquisición en el siglo XVII, Cuenca, Universidad de Castilla-La Mancha, 2006, p. 198.

22. V. Pinto Crespo, «La censura inquisitorial, inquietud e incertidumbre: el caso de Ramon Llull (1559-1610)», Miscelánea de la Universidad Autónoma de Madrid, Cantoblanco, Universidad Autónoma de Madrid, 1982, pp. 293-314. Véanse los trabajos recopilados en S. Muzzi (ed.), Da Raimondo Lullo a Nicola Eimeric. Storia di una falsificazione testuale e dottrinale. Roma Antonianum, 2010; J. y T. Carreras Artau, "Orígenes del antilulismo», Historia de la filosofía española. Madrid, Real Academia de Ciencias Físicas, 1941, pp. 30-44. Véase la documentación del ACA (=Archivo de la Corona de Aragón), R. 4389, ff. 146-148; L. Pérez Martínez, "Lulismo e Inquisición a principios del siglo XvII», en J. A. Escudero (ed.), Perfiles jurídicos de la Inquisición española. Madrid, Universidad Complutense, 1989, pp. 727-751.

23. AHN, Consejo de la Inquisición, legajo 970, ff. 449-455 (antigua numeración, ff. 442-447). Este curso está transcrito en R. Ramis Barceló y P. Ramis Serra, «Comentaria in Artem magnam et paruam’ de Agustín Núñez Delgadillo: un curso luliano manuscrito del siglo XVII", Cuadernos salmantinos de filosofí, 43, 2016, pp. 33-54. 
Tras una lectura atenta del curso, cabe decir que Delgadillo no solamente se situaba en la tendencia lógico-enciclopédica ${ }^{24}$, sino que también se incardinaba en una tradición renacentista del estudio del Arte de Raimundo presente en los Reinos Hispánicos, en Francia, en las ciudades italianas y en el Sacro Imperio.

Tras la prohibición de Zaragoza, Delgadillo recuperó el interés por Llull en Granada y en Madrid, a través del estudio del arte de la memoria. Con todo, el carmelita no solamente tuvo problemas con la Inquisición en Zaragoza, sino que también padeció muchas delaciones ${ }^{25}$ su obra Artificio breve y muy claro para discurrir sin mucho estudio, y con superioridad en toda materia de costumbres ${ }^{26}$. La técnica de esta obra, definida por los calificadores inquisitoriales como "cierto artificio para saber toda la Theologia escolastica y mistica» ${ }^{27}$, se basaba en tomar cien palabras y formular combinaciones entre ellas, a fin de perfeccionar la técnica de la memoria y lograr una forma sencilla de discurrir.

De la misma manera, su obra Breve y fácil declaración del artificio luliano ${ }^{28}$ resulta una muestra harto elocuente de dicha voluntad de establecer el lulismo de forma lógica y retórica, de acuerdo con las modas que tanto éxito tenían en Francia en aquella centuria ${ }^{29}$. Esta obra fue destacada por el padre Sebastián Izquierdo $^{30}$, quien en su Pharus Scientiarum ${ }^{31}$ escribió que había compuesto una Tabla para predicadores, con la cual quería aplicar las excelencias del Arte de Llull a la oratoria sacra. Dicha obra se componía de veinte cuestiones y de cien términos que el predicador tenía que memorizar con el fin de usarlos de forma más correcta y ágil. El propio Izquierdo se refirió asimismo a un discípulo de Núñez Delgadillo, el licenciado Miguel de Vargas, quien dio a las prensas un opúsculo tiempo después en Madrid, intitulado Tesoro de la memoria ${ }^{32}$, con la finalidad de dar mayor difusión a la tabla de su maestro ${ }^{33}$. De hecho, en la Biblioteca Nacional se halla un manuscrito que contiene ambas obras, junto con otras de carácter memorístico, todas ellas de inspiración luliana ${ }^{34}$.

24. S. Trias Mercant, Diccionari d'escriptors lul.listes, UIB-UB, Palma-Barcelona, 2009, p. 303.

25. AHN, legajo 4444, núm. 45, f. $1 \mathrm{v}$.

26. Artificio breve y muy claro para discurrir sin mucho estudio, y con superioridad en toda materia de costumbres. Cuenca, Domingo de la Iglesia, 1627.

27. AHN, legajo 4444, núm. 45, f. $1 \mathrm{v}$.

28. Breve y fácil declaración del artificio luliano, provechosa para todas las facultades, Alcalá, Juan Gracián, 1624.

29. J y T. Carreras Artau, Historia de la filosofía española, pp. 293-295.

30. J. L. Fuertes Herreros, La lógica como fundamentación del arte general del saber en Sebastián Izquierdo: Estudio del "Pharus scientiarum» (1659), Salamanca, Universidad de Salamanca, 1981, p. 245, indica que «Izquierdo habla de este carmelita con una especial simpatía, como si les uniera algún vínculo de amistad».

31. S. Izquierdo, Pharus scientiarum, Lugduni, C. Bourgeat [et] M. Lietard, 1659, p. 283.

32. M. de Vargas, Tesoro de la memoria y del entendimiento y arte facil y breue para toda sabiduría, Madrid, Imprenta Real, 1658.

33. S. Izquierdo, Pharus scientiarum, p. 369.

34. BN, ms. 3353, ff. 1-26 y 90-99. 
Cabe destacar que desde las obras de Pedro de Guevara ${ }^{35}$ hasta Generalis et admirabilis methodus de Pedro Jerónimo Sánchez de Lizárazu, se había desarrollado el lulismo en Castilla, en conexión con Italia (desde Giordano Bruno hasta Placido Perilli ${ }^{36}$ ) y otros lugares de Europa ${ }^{37}$. Frente al lulismo de carácter enciclopédico, convivió otro marcadamente epistemológico (como metasaber) y el arte de la memoria, que fue el ámbito que trabajó especialmente Delgadillo.

Junto con el lulismo, en su obra se encuentran destacados rasgos de la cábala, que proceden de la tradición de cabalística castellana medieval, con autores como José ibn Chiquitilla, discípulo de Abraham Abulafia ${ }^{38}$. Como es sabido, la cábala castellana se desarrolló desde el siglo XIII hasta el XVI, con un acusado carácter sincrético, en el cual se hallaban elementos tanto de la mística del lenguaje, como también de diferentes tendencias que se hallan en el seno de la tradición cabalística (visión extática, teosófica...).

\section{ESTUDIO DE LA OBRA}

Puerta de la luz (1629) es un libro de meditación por medio de letras y combinaciones de letras, por las que se penetra en los misterios cristianos y se ejercen las virtudes. Esta meditación alfabética responde tanto a una visión cabalista, como a la que aplicó Ramon Llull a su sistema filosófico a caballo entre los siglos XIII y XIV. Puerta de la luz, de treinta y tres capítulos, aparece como continuación del libro anterior de Núñez Delgadillo, titulado Minas celestiales y publicado en el mismo año ${ }^{39}$. En síntesis, se perciben en el texto rasgos de lulismo y de la cábala por medio de la memorización del abecedario, a cada letra del cual se da un significado, y hasta varios, pues se configuran diferentes abecedarios temáticos que después podrán ser combinados (como en la Tseruf o ciencia de combinación de letras) y que servirán como punto de referencia para recordar, por ejemplo, un sermón. Sin embargo, en el libro no se encuentran ruedas ni tablas gráficas como las del arte luliano, ni citas explícitas a él. En total la obra presenta ocho abecedarios: de las perfecciones de Dios, de Cristo, de la Pasión de Cristo, del Santísimo Sacramento, de la Virgen

35. R. Ramis Barceló, «El Trivium y el Arte de Llull en La Escala del Entendimiento de Pedro de Guevara», Hipogrifo, 6/2, 2018, (en prensa).

36. R. Ramis Barceló, «El proceso inquisitorial a Dom. Placido Perilli: contexto y nuevos documentos», Revista de la Inquisición, 20, 2016, pp. 63-88.

37. R. Ramis Barceló, «Algunas perspectivas nuevas para la historia del lulismo: referencias lulianas desconocidas en textos impresos del siglo XVI», Antonianum, 90/3, 2015, pp. 583-606.

38. A su vez, existen estudios poco conclusivos sobre la influencia de la cábala en el pensamiento luliano y en el lulismo renacentista, véanse F. Sureda «Cábala y lulismo», en Studia Monographica et Recensiones, vol. 2, Palma de Mallorca, 1948, pp. 16-24; H. Greive, «Ramon Llull i la càbala», Calls, 3, 1988, pp. 75-82, 1988, recuperando también ideas de Josep M. Millàs Vallicrosa.

39. A. Nuñez Delgadillo, Minas celestiales, descubiertas en los Evangelios de Quaresma, distribuidas en sermones, Madrid, Viuda de Luis Sanchez, 1629. 
María, de las virtudes del alma perfecta, de las ofrendas del alma a Dios y de las miserias que originan el pecado mortal.

En Minas Celestiales, el maestro Delgadillo, empleando siempre un lenguaje metafórico y simbólico, había indicado que había puesto todo el cuidado posible de su corta capacidad para exponer los discursos cuaresmales y "he trabajado en que las ponderaciones que doy a la escritura sean en todo rigor verdaderas, porque picantes (assi los llama la agudeza de nuestro siglo) no son verdaderos, sino hipérboles falsos, ofenden nuestra fe, y se desacredita la autoridad del pulpito $^{40} »$. Sin embargo, pese a las cautelas y reservas expresadas en la frase anterior, el carmelita dio a la estampa una obra realmente transgresora, por lo contrastado de sus metáforas y por lo original de su lenguaje, como puede verse en las distintas partes de Puerta de la Luz.

El título coincide con el de la obra del ya citado José ibn Chiquitilla (12481305), Saaré Orá («Las puertas de la luz») ${ }^{41}$. Esta obra, comentario del Zohar, estaba dividida en diez capítulos, o "puertas» que correspondían, en orden ascendente, a las diez sefirot ${ }^{42}$. Cada una de estas puertas se asociaba con uno de los Nombres de la Divinidad que aparecían en la Torá. El estudio de la cábala requería el conocimiento de los atributos y Nombres de Dios, servía para la meditación de los misterios divinos, así como para entender la acción divina en el mundo (desde la creación, Sefer Ha Yetsira). La labor del cabalista no podía ser otra que la de buscar el acercamiento íntimo a Dios y en este sentido puede decirse que la cábala de Chiquitilla tenía un carácter teosófico, que luego tuvo mucha influencia en el pensamiento castellano.

En su obra, el maestro Delgadillo hizo una fusión de esta tradición cabalista con la mística carmelitana y el arte de la memoria. La cábala teosófica y la mística de la reforma carmelitana coincidían principalmente en la penetración en los arcanos divinos a partir del lenguaje y de la metáfora ${ }^{43}$, aunque se diferenciaban en que la cábala tenía un uso más racional-mecánico del lenguaje, mientras que la mística carmelitana castellana quería rebasar las fronteras racionales y buscar la conexión íntima con Dios a través de un sentimiento amoroso lleno de metáforas poéticas. Ciertamente, Puerta de la luz tenía elementos propios de la tradición cabalista castellana arraigada en el siglo XIII, de la mística carmelitana

\section{Minas celestiales, prólogo, s.n.}

41. Hay traducción al inglés por A. Weinstein, Sa'are Orah. Gates of Light. Rabbi Joseph, the son of Abraham Gikatilla, New York 1994.

42. Las más socorridas fueron: 1. Keter Elyón: la suprema corona de Dios. 2. Hojmá: La sabiduría o idea primordial de Dios. 3. Biná: La inteligencia de Dios. 4. Hesed: el amor o la misericordia de Dios. 5. Geburá o Din: el poder de Dios, manifestado como el Dios de Justicia. 6. Rajamim: la compasión de Dios. 7. Netsaj: la infinita paciencia de Dios. 8. Hod: la majestad de Dios. 9. Yesod: la base o el fundamento de todas las fuerzas activas en Dios. 10. Maljut: El reino de Dios como comunidad mística.

43. Indica F. R. de la Flor, «El diagrama: geometría y lógica en la literatura espiritual del Siglo de oro", en Emblemas. Lecturas de la imagen simbólica, Madrid, Alianza Editorial, 1995, pp. 233 256, que «en la tradición gráfica carmelitana se representa en numerosas ocasiones esa estancia interior, que delinea un esquema del alma o de las pasiones, dado a modo de edificio con puertas donde introducirnos y recintos donde ubicar secuenciadamente los conceptos nucleares para la meditación que se desea». 
del XVI, bastante ecléctica (del intelectualismo al misticismo amoroso), y del arte de la memoria barroco.

En la aprobación del libro, por parte de fray Diego del Escorial, se dice: "el $\mathrm{ABC}$ en todas las lenguas es puerta, que franquea entrada a las ciencias», dando sentido al título, Puerta de la luz, pues el abecedario es la puerta que permite la comprensión de los misterios inaccesibles y ocultos y permite la revelación, el acceso a la iniciación del lector ${ }^{44}$. Bajo el aparente método lúdico del alfabeto, expresado con un lenguaje más cotidiano que elevado, hay la vía para la aproximación a lo divino. Pero aparte de la simbología arquitectónica, la noción de puerta de luz (saaré orá) es, como decíamos, un término propio de la cábala, referente a las cincuenta puertas de acceso a Binah, la Inteligencia suprema o sefirot superior. No es extrańo pues, que algunos pasajes del libro fueran acusados de judaísmo y que fuera censurado por parte de la Inquisición ${ }^{45}$, en 1630, un año después de su publicación, quedando así su difusión absolutamente limitada e extinguida si no fuera por el ejemplar que se conserva en el Convento de las Descalzas Reales de Madrid y que aquí presentamos.

Asimismo, el uso del alfabeto como modo de acceso a la divinidad es también un rasgo propio de la cábala ${ }^{46}$, entendido como un «uso experiencial», una «enunciación»o «hiperactivación mental»-usando expresiones de Moshe Idel- que puede conducir incluso a estados místicos y que debía de resultar, sin duda, de un esoterismo muy heterodoxo. Sin embargo, no parece que este sea el objetivo de Puerta de la luz, libro en el que no se habla específicamente de la unión mística, por lo que se ladea este rasgo característico de los carmelitas castellanos.

Sí que se propone, empero, la ejercitación y el aprovechamiento de las almas, como afirma su autor en las últimas líneas del texto. En la dedicatoria y en el prólogo, Núnez Delgadillo propone aproximarse al abecedario con la mentalidad de un niño, como quien empieza a leer, pues desde esa inocencia uno se acerca más al Reino de los Cielos. Impugna así los tratados crípticos, asumiendo la claridad, facilidad y síntesis que aporta un abecedario, que se aprende en la infancia. Su objetivo, rechazando cualquier estilo confuso para el lector, es la evocación de Dios en todas las palabras y pensamientos, y con ella, la mejora y perfeccionamiento de las almas, como los manuales ascético-místicos de oración del siglo XVI, que proponían una vía para iniciados, aprovechados y perfectos. Se trataba de libros destinados a religiosos, tanto para su oración mental -apta también, pues, para un público femenino-como para su labor de

44. M. Eliade, Tratado de Historia de las Religiones, Madrid: Cristiandad, 2000, p. 525-526; J. E. Cirlot, Diccionario de símbolos, Madrid: Siruela, 2006, «Puerta», p. 379.

45. AHN, legajo 4444, núm. 45. Sobre la censura del libro, véase R. Ramis Barceló y A. Serra Zamora, «La censura inquisitorial a Puerta de la Luz de Fr. Agustín Núnez Delgadillo». Revista de la Inquisición, 18, 2014, pp. 81-93.

46. M. Idel, Cábala. Nuevas perspectivas, «La combinación de las letras del nombre divino», pp. 146-153. 
predicadores. Y Puerta de la luz, aparte de ese público fue objeto de curiosidad insatisfecha para muchos escritores que cultivaban el arte de la memoria, que no pudieron manejar la obra, por la interdicción que recaía sobre ella.

\section{Las perfecciones divinas y las imperfecciones humanas}

En el primer capítulo el autor expone la novedad de su método respecto de otros libros, resumida en cuatro aspectos: es un método verdadero y seguro, se basa en una reducción en pocas letras memorizables, está dotado de unas reglas para probar las verdades de la fe y es un artificio agradable que da pie a una buena oración. La tradición de la cábala y del arte de la memoria de orientación luliana están presentes en este primer capítulo, pues uno y otro se basan en letras memorizables y reglas, al tiempo que aseguran que es un mecanismo para la búsqueda de verdad. Como es sabido, para Chiquitilla, la esencia de Dios estaba contenida en el tetragrama YHVH y, en cierto sentido, toda la Torá era, en último término, un tejido hecho con materiales extraídos del tetragrama.

El maestro Delgadillo expresa el contenido a modo de revelación $-\mathrm{y}$ no imitación, puntualiza-, pues confiesa «se me ofreció» $(3)^{47}$, como quien recibe un conocimiento por inspiración divina, y es la revelación lo que da vida a un método que podría parecer repetitivo, automático ${ }^{48}$. En este sentido, operó según los mismos criterios de la revelación de Dios a los místicos y a Llull, así como la iluminación recibida también por los cabalistas.

El fundamento del método empieza con unas definiciones al estilo luliano (5), correspondientes a las perfecciones divinas, bajo los veinte términos siguientes: amor, bondad, centro, duración, eminencia, fin, gloria, hartura, inmensidad, comunicación, luz (desarrollada en la página 8 como liberalidad), misericordia, negación de imperfecciones, omnipotencia, plenitud, quietud, rectitud, sabiduría, todo y vida. Las letras $K, Q$ y $Z$ se sustituyen por palabras que empiezan por $C$. Entre estos términos, los nueve principios del Arte de Llull (bondad, grandeza, eternidad, poder, sabiduría, voluntad, virtud, verdad y gloria) se encontraban junto a otros procedentes del vocabulario místico (amor, centro, gloria, hartura, luz, negación de imperfecciones, plenitud, quietud, sabiduría, todo), así como otros procedían de la tradición cabalista (rectitud, comunicación, sabiduría ${ }^{49}$ ). La luz era omnipresente, común a todas las tradiciones, especialmente la cabalista y la neoplatónica. La emanación de la

47. A lo largo del apartado, se incorporan entre paréntesis las páginas referentes al volumen de Puerta de la luz.

48. M. Idel, Cábala. Nuevas perspectivas, p. 149.

49. Son rasgos propios de la cábala tanto antigua como moderna, muy presentes tanto en la cábala castellana como en la de autores como Isaac Luria. Véase E. Klein, The Kabbalah of Creation: The Mysticism of Isaac Luria, Founder of Modern Kabbalah, Berkeley, North Atlantic Books, 2005. 
luz de las sefirot tenía lugar en Dios, y en este proceso, el hombre podía percibir a Dios, que se hacía patente en el mundo finito de la creación.

En el segundo capítulo se explica la fundamentación del abecedario, afirmando que Dios está en cada letra y en todo el abecedario entero al mismo tiempo, de modo que Dios reside en todas partes (12-19), en el lenguaje y en aquello que el lenguaje representa, en una forma que podríamos denominar panteísmo lingüístico.

En esta línea, el autor habla de cinco semejanzas: 1) todo está en todo; 2) la analogía entre Cristo, Dios y la Hostia, y entre el abecedario general, la letra concreta y Dios; 3) la analogía entre la Santísima Trinidad, la Hostia y el Cáliz; 4) bocado de vida - bocado de muerte; y 5) accidentes consagrados. Esta omnipresencia de Dios supone la relación entre las perfecciones divinas, en sí mismas y entre ellas (cap. III, 19-28). Después de especificar las definiciones y los principios (20-22), el autor procede a lo que llama la ponderación del abecedario (23) que es el encadenamiento de las perfecciones por orden alfabético, de la $\mathrm{A}$ a la $\mathrm{V}$ y a la inversa (25-27).

Una vez expuestas las veinte perfecciones divinas, Delgadillo presenta las veinte imperfecciones de las criaturas, que se definen por la negación de las perfecciones de Dios (cap. IV, 29-38). Si Dios se define por ser amor absoluto, «la criatura no nos ama con amor infinito» (29v). Aquí, Dios definido como bondad infinita, nos recuerda a las dignidades lulianas. Por este motivo es tan importante rezar las letanías por las cuales se invoca la liberación de los peligros por parte de las perfecciones ( Amor divino, liberadme de este peligro; Bondad infinita, liberadme de este peligro») de modo que estas actúen en el devoto junto con la intercesión de los santos (cap. V, 38-42).

En el capítulo sexto (42-50v) se ponderan y relacionan los pecados mortales según el abecedario, con lo cual se determina la gravedad del pecado: «en cada perfección de estas veinte, hay diecinueve grados que declaran otros tantos de la gravedad de la ofensa» (45). Una ofensa a Dios, en consecuencia, equivale a una ofensa a las veinte perfecciones y a los diecinueve grados de cada una de ellas. Siguiendo la tradición mística, se afirma que la perfección de Dios resulta dolorosa al hombre pues este último ve, en contraste, su naturaleza imperfecta. Sin embargo, ahí el abecedario de la perfección de Dios sirve para alentar la esperanza del devoto (cap. VII, 50v) pues cada letra acoge una perfección divina (cap. VIII, 52v-56) y así Dios deviene omnipresente a través del uso de lenguaje. Se trata de un método de tipo intelectualista y, en este sentido, más luliano que carmelitano. Los ejemplos que propone para aplicar la perfección asignada a cada letra son palabras cotidianas: ay, Pedro, pan, agua, diamante, flor, soldado, recebi [sic], rey, hecho que fue señalado en las censuras inquisitoriales posteriores como una inadecuación indigna y un menosprecio a Cristo ${ }^{50}$.

El capítulo noveno (56) prosigue con un análisis alfabético-cabalístico de la palabra Dios y de las perfecciones (amor, bondad, centro) que permanecen en las

50. Censura del P. Pineda, AHN, legajo 4444, núm. 45, f. 1v. 
letras (56v), por las cuales se hace presente Dios en las palabras y en el mundo, y por ellos debe ser amado (mundo, honra, riquezas, deleite, cap. X, 57v). Son precisamente los nombres, con sus letras que evocan las perfecciones, los que dan al alma motivos para no pecar, como se demuestra con el análisis alfabético de la palabra hermosura (cap. XI, 63v-66v), de modo que en el lenguaje radica un poder salvífico. El capítulo duodécimo (66v) pondera los beneficios de Dios a propósito de su Encarnación y del Santísimo Sacramento, leídos a la luz del abecedario, hecho que enriquece la oración. El capítulo siguiente trata de las ventajas que Dios da a reyes y señores, cuyas cualidades, limitadas, no se deben confundir con las de Dios. En este sentido, la obra del maestro Delgadillo se inserta dentro de la cultura del Barroco español, al ser un guiño a la Monarquía católica, de la que el carmelita era un fiel seguidor y defensor.

En el capítulo XIV (74v), Núńez Delgadillo proporciona cuatro reglas para examinar el espíritu y el estado de perfección, dos de ellas son positivas y dos son negativas. En primer lugar, se dice que lo que está vinculado a las perfecciones es bueno y que lo que concuerda con una perfección, concuerda con todas. Las dos reglas negativas afirman que lo que desdice a las perfecciones es malo y que lo que no concuerda con una, desdice de todas. Por este motivo es de gran importancia llevar el abecedario en la memoria $(75 \mathrm{v})$ y conocer las diecinueve reglas de amor (76v). Según el autor, la práctica del alfabeto a partir de estas reglas conlleva cuatro provechos (cap. 15, 77v): 1) que lo que concuerda con una perfección concuerda con todas, 2) da un método para escribir un libro sobre Dios, 3) es útil para que los predicadores ponderen la gravedad de los pecados y 4) resulta de interés para que los predicadores desarrollen un lugar de escritura.

Núnez Delgadillo se plantea asimismo el problema de la repetición, dado que los elementos del abecedario son cerrados, como sucedía en la tradición luliana. Con el objetivo de paliar este aspecto, en el capítulo XVI se dan unas reglas para extender los discursos del abecedario sin repetir significaciones, hecho que sucede porque las letras, aun siendo las mismas, toman sentidos diferentes según la posición que ocupan (por ejemplo, la primera a de la palabra María no tiene el mismo sentido que la segunda $a$ ).

\section{Abecedarios de Jesucristo, de la Pasión y del Santísimo Sacramento}

Seguidamente el autor presenta un nuevo abecedario, llamado de iesu cristo, con cinco usos y provechos (cap. XVII, 86v). Las veinte letras se refieren en este caso a veinte nombres de Cristo, una tradición ya presente en la Biblia y con una notable continuación en el humanismo castellano, como por ejemplo en Fray Luis de León. Contrasta la magnificencia de los nombres con los ejemplos en los que Núnez Delgadillo aplica su método, como la palabra gusano. Siguen a estos ejemplos, las letanías pertinentes («abogado, líbrame deste peligro»). Por este abecedario se ponderan tanto los beneficios recibidos de Cristo como los pecados cometidos contra Cristo (cap. XVIII). La misma lista de pecados, como se verá, da motivos para no pecar (cap. XIX, cap. XXI). 
Por ejemplo, de acuerdo con el tenor de la obra, si cogemos la palabra venganza y le aplicamos el abecedario de Cristo a cada letra, veremos el sinsentido de ser vengativo, pues las letras llaman a la virtud y es así como aplicando el alfabeto a todas las palabras se dibuja el camino de las virtudes en cada cosa y acción. El mismo procedimiento se aplica a la palabra murmuración. En el capítulo vigésimo se aplican los elementos de la Pasión de Cristo al abecedario, creando así pues un tercer abecedario, después del de las perfecciones de Dios y el de Cristo. Los provechos que presenta esta alfabetización de la Pasión son principalmente dos: que cada letra tiene un paso de la Pasión y que permite ir ponderando cada paso de la Pasión a través de los otros. Seguidamente se aplica el abecedario a las palabras agua, flor, galas y perdiz.

Los ejemplos propuestos por el maestro Delgadillo podían resultar extrańos. En el libro puso un ejemplo que después ha sido muy socorrido: «si comes una perdiz mira las letras de la P. E. R. D. I. Z. y hallarás la prision de tu amado: el escarnio que del hizieron: el rigor con que lo trataron: el desamparo que padecio: la injusticia, y la Cruz, usando de la C. por Z. con estos picantes come la perdiz.» (103v-104r). Como puede imaginarse, la Inquisición fue especialmente crítica con estos pasajes, en los cuales detectó un cierto sabor judaizante, que ya comentamos en nuestro estudio ${ }^{51}$ de la censura que hizo el P. Pineda ${ }^{52}$. Cabe destacar que autores de nuestro tiempo como Piedad Bolańos han considerado que la alusión a la perdiz tenía un significado alegórico y que el P. Pineda vinculaba en la censura el hecho de no comer perdiz con un rasgo del judaísmo ${ }^{53}$. Por nuestra parte, creemos que la intención más profunda del P. Pineda no fue esa: más bien, el tenor de la censura muestra que para el jesuita la minusvaloración de Cristo en el texto de Núńez Delgadillo tenía sabor judaizante, por no conceder suficiente importancia al Verbo encarnado, el cual, no obstante, fue protagonista indiscutible de otros pasajes de la obra, enaltecido siempre de acuerdo con la ortodoxia católica. Asimismo, si atendemos en términos generales al significado simbólico de la perdiz en la tradición occidental, para Juan Eduardo Cirlot destaca el afán acumulador de riquezas de dicho animal y a su capacidad engañosa a través de su canto ${ }^{54}$, rasgos que solían criticarse de los judíos.

Volviendo al abecedario, hay que recalcar que, según el maestro Delgadillo, sirve para tener paciencia en los trabajos -como Cristo en su sufrimientoy perdonar de corazón (cap. XXII, 107v) a la vez que sirve para las letanías y deprecaciones (cap. 23, 110): «Por vuestros azotes, dadme buena muerte», cogiendo en este caso la palabra azotes asignada a la letra $a$.

51. R. Ramis Barceló y A. Serra Zamora, «La censura inquisitorial...», pp. 88-89.

52. AHN, legajo 4444, núm. 45, f. $1 \mathrm{v}$.

53. P. Bolaños, La obra dramática de Felipe Godinez, Sevilla, Diputación Provincial de Sevilla, 1983 , p. 57 «Extendida debería estar, también, la versión que dio Fray Agustín Delgadillo de la palabra PERDIZ, queriendo demostrar que todo aquel que no la comiera menospreciaba a Cristo, sus misterios y en él había olor a judaísmo».

54. J. E. Cirlot, Diccionario de símbolos, p. 363. 
A continuación (cap. XXIII [sic], p. 114) se aplica el abecedario del Santísimo Sacramento con los mismos provechos (p. 114r-v). Para ilustrar su funcionamiento, se aplica el abecedario a las palabras tierra, gallina, venganza e impaciencia. Veamos como lo articula el autor con el ejemplo de la gallina:

Como una gallina. Miro las letras del nombre G. A. L. L. I. N. A. y con la G. hallo gustos sacramentales. En la A. alimento del alma. E la L. lazo de Christo y el alma. En la I. invencion de amor. En la N. nube que cubre el Sol de justicia. Y voy ponderando, que diferente manjar de la gallina es el santisimo Sacramento, comparando gustos con gustos, alimento con alimento, \&c. (116v).

El mismo capítulo continúa con cuatro modos de deprecaciones ([sic], $188 \mathrm{v})$ : 1) suplicar un aumento de gracia (ejemplo: «Alimento de las almas, dadme aumento de gracia»); 2) rezar al Padre eterno y al Espíritu Santo; 3) pedir un aumento de gracia a la Virgen; y 4) pedirlo al santo o al ángel que se quiera. Asimismo se aplica el abecedario para despreciar los regalos del mundo ([sic], 121), es decir, para rechazar los bienes materiales.

\section{Combinación de abecedarios}

Finalmente, llega el momento de juntar los cuatro abecedarios que el autor ha presentado hasta este punto (cap. XXV, 123-124v): el de Dios, el de Cristo, el de la Pasión y el del Santísimo Sacramento, de un modo sintético que el maestro Delgadillo considera fácilmente memorizable. Alaba los provechos de la unión de estos abecedarios pues contienen los misterios de Dios y permiten mezclarlos. La combinatoria permite un ejercicio especulativo con los términos meditativos, como se muestra en la Tabla 1 .

\begin{tabular}{|l|l|l|l|l|}
\hline & $\begin{array}{l}\text { Abecedario de } \\
\text { lasperfecciones } \\
\text { divinas }\end{array}$ & $\begin{array}{l}\text { Abecedario } \\
\text { de Jesucristo }\end{array}$ & $\begin{array}{l}\text { Abecedario } \\
\text { de la pasión } \\
\text { de Cristo }\end{array}$ & $\begin{array}{l}\text { Abecedario del } \\
\text { Santísimo } \\
\text { Sacramento }\end{array}$ \\
\hline A & amor & abogado & azotes & alimento de almas \\
\hline$B$ & bondad & brazo de Dios & bofetadas & bebida celestial \\
\hline$C$ & centro & camino seguro & calumnia & carne de Jesucristo \\
\hline$D$ & duración & $\begin{array}{l}\text { deseado de } \\
\text { las gentes }\end{array}$ & desamparo & dulzura varia \\
\hline$E$ & eminencia & $\begin{array}{l}\text { esposo de } \\
\text { las almas }\end{array}$ & escarnio & exceso de amor \\
\hline$F$ & fin & $\begin{array}{l}\text { fiador de los } \\
\text { hombres }\end{array}$ & fatiga & firmeza de la Iglesia \\
\hline$G$ & gloria & guía para el cielo & grito & gustos espirituales \\
\hline
\end{tabular}




\begin{tabular}{|c|c|c|c|c|}
\hline$H$ & hartura & $\begin{array}{l}\text { hijo de Dios y de } \\
\text { María }\end{array}$ & hiel & hostia consagrada \\
\hline$I$ & inmensidad & juez rectísimo & injusticia & invención de amor \\
\hline$K(C)$ & comunicación & consejero & cruz & combate universal \\
\hline$L$ & luz & legislador & lanza & $\begin{array}{l}\text { lazo de Dios y del } \\
\text { alma }\end{array}$ \\
\hline$M$ & misericordia & maestro & muerte & misterio de fe \\
\hline$N$ & $\begin{array}{l}\text { negación de } \\
\text { imperfecciones }\end{array}$ & norte de la Iglesia & negación & $\begin{array}{l}\text { nube que cubre el } \\
\text { sol de justicia }\end{array}$ \\
\hline$O$ & omnipotencia & $\begin{array}{l}\text { ofrenda por } \\
\text { pescadores }\end{array}$ & oración & olvido de la vieja ley \\
\hline$P$ & plenitud & pastor & prisión & prenda de gloria \\
\hline$Q(C)$ & quietud & cordero & corona & cordero pascual \\
\hline$R$ & rectitud & rey & rigor & $\begin{array}{l}\text { regalo de la mesa de } \\
\text { Dios }\end{array}$ \\
\hline$S$ & sabiduría & sacerdote & sudor & sacrificio incruento \\
\hline$T$ & todo & triunfante & tristeza & tesoro escondido \\
\hline$V$ & vida & vencedor & venta & viático para el cielo \\
\hline
\end{tabular}

Tabla 1. - Abecedarios de las perfecciones de Dios, de Cristo, de la Pasión de Cristo y del Santísimo Sacramento

Los doce provechos de la unión empiezan por el hecho de que en cada letra están presentes los cuatro misterios de los cuatro abecedarios; además se puede articular un término con los tres términos correspondientes a los tres abecedarios restantes, e incluso con los setenta y nueve otros términos de todas las otras letras de su abecedario y de los otros tres $(20+20+20+19)$. Núñez Delgadillo propone usar la combinación de términos como acción de gracias a Dios. Se trata de la proyección más específicamente cristiana de la obra, que de aquí en adelante tiene un marcado sentido contrarreformista, basándose en la Virgen y el Santísimo Sacramento.

El capítulo XXVI está dedicado a ahondar en los siguientes cuatro provechos de resultas de juntar los cuatro susodichos abecedarios (133v-136). En primer lugar, Delgadillo hace notar que los abecedarios son cuatro motivos para estar agradecidos a Dios, y en cada letra se pueden hallar cuatro motivos para ponderar el pecado y para menospreciarse a uno mismo, al mismo tiempo 
que en cada nombre o criatura se hallan, por medio del abecedario, los títulos de Dios, del Santísimo Sacramento, etc., y así se puede ejercer su imitación. Se ponderan los cuatro últimos provechos de estos cuatro abecedarios en el capítulo XXVII (136), en el que se sostiene que: son útiles para construir oraciones jaculatorias; permiten tener una idea perfecta de Dios, su Pasión y Sacramento; permiten ponderar cualquier discurso y lugar de escritura para predicadores; y funcionan para hacer alarde de lo que es Dios en sí (abecedario de las perfecciones divinas), Dios como hombre (abecedario de Cristo), Dios en su Pasión (abecedario de la Pasión) y Dios en el Santísimo Sacramento (abecedario del Santísimo Sacramento).

\section{Otros cuatro abecedarios}

La obra prosigue con intención mariológica, con el fin de lograr la edificación de la piedad del lector. El capítulo XXVIII presenta un abecedario de la Virgen Santísima María (148v) a cuyos términos siguen sus cuatros provechos: el hecho de que en cada letra se halle a la Virgen; la presencia de la Virgen en todo lo que hacemos y decimos; la declaración de la dignidad de María; y en cuarto lugar, la conjunción de Madre e Hijo en cada letra. Se propone, en el capítulo siguiente (151), una letanía para cada letra del abecedario de la Virgen. Por ejemplo, a la letra A le corresponde «abogada mía, dadme vuestro favor». El capítulo trigésimo recoge las virtudes del alma perfecta, que son, una vez más, veinte. Siguen las letanías y deprecaciones a Dios («amor divino, dadme vuestro amor», «bondad infinita, dadme vuestra bondad universal»...), a Cristo y a la Virgen por la Pasión de Cristo.

La mariología de Delgadillo no sólo debe atribuirse a su tradición carmelita, sino al afán mariológico luliano, patente en los franciscanos y en los seguidores del Doctor Iluminado a lo largo de toda la Modernidad. Para Llull, toda la obra divina ad extra pasaba por la Virgen María, pues en ella se celebró la alianza entre Dios y la naturaleza humana. Después de Cristo no había criatura más cercana a Dios que la Virgen María, porque en ella se manifestó con mayor claridad el amor de Dios y es donde se produjo la Encarnación. Este hecho situaba María por encima de las otras criaturas, pues ella era el medio de transmisión de esta acción divina: todas las dignidades entraron en el mundo a través de María y de su hijo, que era el Hijo de Dios ${ }^{55}$. Esta exaltación fue llevada al extremo por Delgadillo en el Abecedario de la Virgen, donde se destaca que era A (Abogada nuestra), B (Bendita entre las mujeres) y C (Concebida sin pecado original), recalcando su fiel adscripción al inmaculismo luliano.

55. Véase F. Domínguez Reboiras, «El discurso luliano sobre María», Gli studi di mariologia medieval. Bilancio storiografico. Atti del I Convegno Mariologico della Fondazione Ezio Franceschini. Parma 7-8 novembre 1997, ed. Clelia Maria Piastra, Sismel: Edizioni del Galluzzo, 2001, pp. 277-303, especialmente p. 291. 
Continuando con la tónica de los abecedarios anteriores, Núñez Delgadillo propone un abecedario con las palabras referidas a lo que se tiene que ofrecer a Dios cada mañana (cap. XXXI). La ofrenda a Dios a través de este abecedario y el de las perfecciones divinas sería: «amor infinito, ofrézcote mi alma...»; la combinación con la ofrenda a Cristo sería: «advocado nuestro, ofrézcote mi alma...» y con la Virgen resultaría: «abogada nuestra, en vuestras manos pongo mi alma» (163v).

En el capítulo XXXII se presenta el último abecedario, de las miserias de las que nace el pecado mortal (165v). Los cinco provechos pertinentes son: 1) en cada letra se ve un efecto del pecado para temer cometerlo; 2) a través de las letras se ve en todas las cosas un efecto del pecado (por ejemplo, al analizar la palabra perdiz); 3) hallar en el pecado mismo, sus miserias, y llorar si se ha cometido; 4) ir careando este abecedario con el de las perfecciones divinas; 5) declarar una miseria del pecado por las otras que se dicen en las letras. Las letanías de este abecedario se articulan como este ejemplo: «amor infinito, liberadme de vuestro aborrecimiento» (170r).

\begin{tabular}{|c|c|c|c|c|}
\hline & $\begin{array}{l}\text { Abecedario de la } \\
\text { Virgen María }\end{array}$ & $\begin{array}{l}\text { Virtudes del } \\
\text { alma perfecta }\end{array}$ & $\begin{array}{l}\text { Ofrendas del } \\
\text { alma a Dios }\end{array}$ & $\begin{array}{l}\text { Miserias de } \\
\text { las que nace el } \\
\text { pecado mortal }\end{array}$ \\
\hline$A$ & abogada nuestra & amor de Dios & alma & $\begin{array}{l}\text { aborrecimiento } \\
\text { de Dios }\end{array}$ \\
\hline$B$ & $\begin{array}{l}\text { bendita entre } \\
\text { las mujeres }\end{array}$ & bondad universal & bienes & bajeza de ánimo \\
\hline$C$ & $\begin{array}{l}\text { concebida sin } \\
\text { pecado original }\end{array}$ & conversión & corazón & $\begin{array}{l}\text { ceguedad del } \\
\text { entendimiento }\end{array}$ \\
\hline$D$ & deífica & dolor de pecados & deseos & $\begin{array}{l}\text { desorden de } \\
\text { voluntad }\end{array}$ \\
\hline$E$ & $\begin{array}{l}\text { esperanza } \\
\text { nuestra }\end{array}$ & esperanza viva & empleo & esclavitud infame \\
\hline$F$ & fuente sellada & fe viva & familia & $\begin{array}{l}\text { fealdad } \\
\text { abominable }\end{array}$ \\
\hline$G$ & $\begin{array}{l}\text { graciosa a los } \\
\text { ojos de Dios }\end{array}$ & gracia & gobierno & $\begin{array}{l}\text { gemir } \\
\text { eternamente por } \\
\text { un gusto soñado }\end{array}$ \\
\hline$H$ & huerto cerrado & humildad & hijos & hijo del diablo \\
\hline$I$ & $\begin{array}{l}\text { intercesora } \\
\text { nuestra }\end{array}$ & justicia & iglesia & ingratitud \\
\hline
\end{tabular}




\begin{tabular}{|c|c|c|c|c|}
\hline$K(C)$ & $\begin{array}{l}\text { coronada de } \\
\text { estrellas }\end{array}$ & $\begin{array}{l}\text { conformidad } \\
\text { con Dios }\end{array}$ & cuidados & $\begin{array}{l}\text { caída de la } \\
\text { gracia de Dios }\end{array}$ \\
\hline$L$ & $\begin{array}{l}\text { lirio entre } \\
\text { espinas }\end{array}$ & luz & lengua & $\begin{array}{l}\text { lazo de donde } \\
\text { no puede salir si } \\
\text { Dios no lo saca }\end{array}$ \\
\hline$M$ & $\begin{array}{l}\text { madre de } \\
\text { misericordia }\end{array}$ & $\begin{array}{l}\text { menosprecio de } \\
\text { sí y del mundo }\end{array}$ & muertos & $\begin{array}{l}\text { miseria digna } \\
\text { de ser llorada } \\
\text { por todos }\end{array}$ \\
\hline$N$ & navío de pan & $\begin{array}{l}\text { negación de } \\
\text { sí mismo }\end{array}$ & necesitados & $\begin{array}{l}\text { naufragio de } \\
\text { merecimientos }\end{array}$ \\
\hline$O$ & oveja mansísima & oración & oficio & $\begin{array}{l}\text { ofensa contra } \\
\text { una majestad } \\
\text { infinita }\end{array}$ \\
\hline$P$ & paloma sin hiel & paciencia & $\begin{array}{l}\text { padres } \\
\text { espirituales } \\
\text { y carnales }\end{array}$ & $\begin{array}{l}\text { pérdida de } \\
\text { dios y su cielo } \\
\text { para siempre }\end{array}$ \\
\hline$Q(C)$ & $\begin{array}{l}\text { compañera } \\
\text { de Dios }\end{array}$ & castidad & contrarios & $\begin{array}{l}\text { condenación } \\
\text { eterna }\end{array}$ \\
\hline$R$ & $\begin{array}{l}\text { reina de los } \\
\text { cielos }\end{array}$ & resignación & $\begin{array}{l}\text { rey y reino } \\
\text { república }\end{array}$ & $\begin{array}{l}\text { rigor con su } \\
\text { alma mayor que } \\
\text { todos los rigores } \\
\text { de dios con los } \\
\text { condenados, } \\
\text { pues mayor mal } \\
\text { es un pecado } \\
\text { mortal que la } \\
\text { pena que se da } \\
\text { por ella, que } \\
\text { esta es santa } \\
\text { y justificada }\end{array}$ \\
\hline$S$ & $\begin{array}{l}\text { sagrario del } \\
\text { Espíritu Santo }\end{array}$ & sabiduría & sacerdotes & $\begin{array}{l}\text { soledad sin dios } \\
\text { y contra dios }\end{array}$ \\
\hline$T$ & torre de David & temor de Dios & $\begin{array}{l}\text { tiranos que } \\
\text { Dios los } \\
\text { convierta }\end{array}$ & tinieblas eternas \\
\hline$V$ & $\begin{array}{l}\text { virgen y madre } \\
\text { de Dios }\end{array}$ & unión con Dios & $\begin{array}{l}\text { victoria } \\
\text { contra infieles }\end{array}$ & $\begin{array}{l}\text { vender el alma } \\
\text { al demonio por } \\
\text { un gusto breve }\end{array}$ \\
\hline
\end{tabular}

Tabla 2. - Abecedarios de la Virgen María, de las virtudes del alma perfecta, de las ofrendas del alma a Dios y de las miserias de las que nace el pecado mortal 
En la tabla aparecen algunos tópicos de la liturgia de las horas, del Santo Rosario (torre de David, coronada de estrellas, lirio entre espinas...) así como otros más elaborados, sobre todo en la tabla de las miserias en las que nace el pecado mortal. Las virtudes del alma perfecta son las propias de aquella que tiene una íntima comunión con Dios, de manera que coinciden en buena manera con los atributos lulianos o las diez sefirot ${ }^{56}$.

\section{Arte de la memoria}

En el último capítulo de Puerta de la luz se evidencia que la propuesta de Núñez Delgadillo es un arte para la memoria y que el autor trata de destacarlo entre otros métodos con objetivos semejantes (171v-178). El artificio que presenta -afirma el autor- es fácil, provechoso, eficaz y no lleva a confusión. Añade recomendaciones sobre cómo disponer un sermón (173), dividir los puntos importantes y estudiar los lugares con los que trabaja la memoria a partir del uso de letras que ordenan las partes del discurso. Por ejemplo, el orador puede recordar la palabra amor porque amor se vincula a sum (Dios es amor) y el orador quiere hablar de sum qui sum y la palabra amor da la primera posición del discurso porque es la primera letra del abecedario. Asimismo, para favorecer la memorización cuando uno empieza a familiarizarse con el uso del abecedario, se puede disponer de las concordancias, es decir, tenerlas a la vista en la celda. Eso sugiere que se trata de una obra de lectura y de ejercitación personal, en la meditación individual y en la preparación de los sermones.

Esta dimensión alfabética del arte de la memoria permite asociar una palabra a un lugar en el discurso y a una imagen determinada, presente físicamente o puramente mental, a fin de presentar esquemáticamente el núcleo de lo predicable o meditable, susceptible de una operación personal de amplificatio retórica a través de los loci.

Los cinco primeros abecedarios de Núñez Delgadillo (Dios, Cristo, Pasión, Sacramento, Virgen) dan un orden de cien lugares de la memoria, útiles tanto para artistas (filósofos), como también para médicos, juristas o embajadores, pues se presenta como un método universal, aspiración propia de la tradición luliana para tratar cuestiones como matrimonios, guerras, sucesos e incluso para recordar la lista de los reyes de la historia de España. Esta última parte es la más específicamente barroca y contrarreformista, al servicio de la monarquía hispánica.

En el siglo XviI, sobre todo fuera de las universidades, se hizo una lectura mecánica y combinatoria de Llull, que prescindió de toda la carga metafísica, que estaba en el corazón de la filosofía luliana de los siglos XV y XVI. La

56. Reflexiona sobre la semejanza entre las dignidades lulianas y las sefirot judías J. M. Vallicrosa, "Algunas relaciones entre la doctrina luliana y la Cábala», en Nuevos estudios sobre historia de la ciencia española, Barcelona, 1960, pp. 259-270; publicado primeramente en Sefarad, 18, 1958, pp. 241-253. 
explicación más plausible de este cambio, más allá de la moda racionalista, fue la edición de una antología de textos lulianos ${ }^{57}$, que contenía obras auténticas y espurias (pseudoalquímicas) de Llull, junto con comentarios de Agrippa y Bruno $^{58}$.

Indica Fernando R. de la Flor que «la misma concepción de esa potencialidad de la memoria a la altura del siglo XVII, había sido todavía considerablemente ampliada por las versiones hermetistas brunianas que concurren en la teoría del

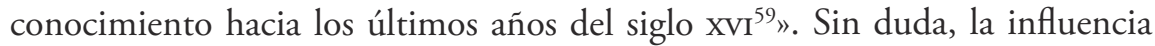
del Arte bruniano de la memoria se encuentra en Delgadillo. Muchas son las coincidencias, aunque solo haremos referencia a dos.

En primer lugar, el tema de la luz. Para el Nolano, la luz se revela en la imagen, que es, al fin y al cabo, lo iluminado, a saber, el acto sensible y la forma de las cosas. La Puerta de la luz del maestro Delgadillo es el acceso a la luz metafísica por la cual podemos captar las imágenes de las cosas naturales y también las divinas. En segundo lugar, la necesidad de combinar elementos diferentes en su vocación retórico-epistémica: las tablas de Delgadillo y los célebres atrios de Bruno.

Recordemos que para el Nolano había veinticuatro atrios dispuestos en un diagrama: cada atrio tenía un nombre propio, que seguía, al igual que hace Delgadillo en su obra, las letras del alfabeto. Así, por ejemplo, A era Altar, B era Basílica, C era Cárcel. Su emplazamiento venía dado por la propia secuencia de las letras. Ignacio Gómez de Liaño indica que, en el caso de Bruno, se trataba de veinticuatro lugares-sujetos particulares ${ }^{60}$.

El lulismo bruniano, pese a sus particularismos, comprendía diferentes facetas: Arte, lógica, medicina, metafísica ${ }^{61} \ldots$ y su propagación en diversos centros académicos favoreció, sin duda, el interés por la obra de Llull en toda Europa: en Francia y en el Sacro Imperio, así como en Oxford y en otras partes de Inglaterra, donde el lulismo fue propagado como doctrina hermética y alquímica.

El arte de la memoria de filiación luliana resultaba muy interesante para autores franceses, especialmente en el ámbito de la predicación y de la espiritualidad. Debemos citar a dos de ellos, que pueden incardinarse asimismo en la corriente retórico-utilitaria ${ }^{62}$ del ars praedicandi, que tiene mucha relación con esta obra del maestro Delgadillo: Jean Belot y Hugues Carbonel. El segundo era un franciscano observante, que escribió Artis lulliane

57. Raymundi Lulli Opera ea quae ad adinventam ab ipso Artem universalem, Estrasburgo, Zetzner, 1598.

58. Véase, en un sentido general, I. Rowland, Giordano Bruno: Philosopher/Heretic, Chicago, Chicago U.P., 2009, pp. 100-121.

59. F. R. de la Flor, Mundo simbólico: Poética, politica y teúrgia en el Barroco hispano, Tres Cantos, Akal, 2012, p. 97.

60. I. Gómez de Liaño, Iluminaciones filosóficas, Madrid, Siruela, 2001, p. 455.

61. P. Rossi, Clavis universalis: Arti mnemoniche e logica combinatoria da Lullo a Leibniz (Milano-Napoli, 1960), 109-123.

62. J. y T. Carreras Artau, Historia de la filosofía española, pp. 294-295. 
seu memorice artificialis ${ }^{63}$, mientras que el primero era un abogado del consejo privado de Luis XIII, autor de obras como La Rhétorique ${ }^{64}$ y un Traicté de la memoire artificielle ${ }^{65}$. Ambos habían preparado sus obras con una intención muy similar a la de Núnez Delgadillo. En Francia, dicha corriente basada en el arte de la memoria entroncó con otra de carácter enciclopédico, en la cual destacaron obras como L'art de bien discourir ${ }^{66}$ de Nicolas Hauteville. En España, la línea lógico-mnemotécnica del maestro Delgadillo no tuvo destacados continuadores, aunque se prolongó, de forma ya claramente decadente, hasta el siglo XVIII, con figuras como Francisco José de Artiga ${ }^{67}$, que pueden ser considerados como una degeneración de esta tradición.

Sin embargo, entre los jesuitas contemporáneos al maestro Delgadillo hubo verdaderos especialistas en Llull, como el ya citado Sebastián Izquierdo, que enseñó en Alcalá y en Madrid o Athanasius Kircher, que lo hizo en Roma. Izquierdo y Kircher integraron a Llull en el enciclopedismo de su época e influenciaron a otros jesuitas eruditos como Gaspar Knittel o Gaspar Schott. Asimismo su afinidad luliana les permitió abrir sendas en la matemática, lógica y arte de la memoria que se tradujeron en numerosos escritos, que influenciaron profundamente a muchos autores europeos.

Otros tratadistas de filosofía y teología escolástica (especialmente carmelitas y mínimos en Francia, y benedictinos en España) hicieron numerosas referencias al pensamiento de Llull, tanto en el XVII como en el XVIII, y las integraron en manuales escolásticos ${ }^{68}$. Entre los mínimos franceses cabe destacar a Jean Lalemandet, Emmanuel Maignan y Pierre de Rians, autor éste de una introducción al Arte de Llull.

Esta obra también se enmarca en la tendencia hispana del arte de memoria. No en vano, pocos años antes se había publicado el Fénix de Minerva ${ }^{69}$ de Velázquez de Acevedo, estudiado magistralmente por F. R. de la Flor, que contenía la aprobación del maestro Delgadillo ${ }^{70}$.

63. H. Carbonel, Artis lulliane seu memoric artificialis secretum explicitum oratoribus et predicatoribus utilissimum, Paris, apud Joannem Laguehay, 1620.

64. J. Belot, La Rhétorique par la quelle on peut discourrir de ce qui est prope en l'oraison et disputable par dialectique, selon la subtilité de l'art lulliste et autres arts plus secrets, París, 1623, con múltiples reimpresiones.

65. J. Belot, Traicté de la memoire artificielle où l'art de Raymond Lulle, Rouen, 1640, con varias reimpresiones.

66. N. de Hauteville, L'art de bien discourir, ou la méthode aysée pour inventer, former, établir et multiplier un solide discours dans la Chaire et dans le Barreau. Paris, chez Thomas Jolly, 1666.

67. M. A. Díez Coronado, «Francisco José de Artiga y la retórica del siglo Xvir. Epitome de la elocuencia española (1692)», Alazet, 14 (2002), pp. 201-207.

68. R. Ramis Barceló, «La presencia de Ramon Llull en la filosofía escolástica del siglo XVII», Argumenta Philosophica, 2, 2016, pp 51-68.

69. J. Velázquez de Acevedo, Fenix de Minerva y Arte de Memoria, Madrid, Juan González, 1626.

70. F. R. de la Flor, Teatro de la memoria. Siete ensayos sobre mnemotecnia española de los siglos XVII y XVIII. Salamanca, Junta de Castilla y León, 1996, p. 48. 
Este artificio, en definitiva, más allá de su valor en la predicación, sirve para que no se olvide lo estudiado, es decir, primero se tiene que memorizar el contenido. Está claro que Núnez Delgadillo se quiere incardinar en la tradición del ars memoriae al hablar de lugares (los loci, en un sentido físico) pues se refiere a la idea de un edificio del cual se recorren los aposentos, dotados previamente de un significado para el discurso en cuestión. Esta idea aparece en las Instituciones oratorias de Quintiliano y se desarrolla en la tradición del teatro de la memoria de orientación luliana, bien estudiada por Frances A. Yates ${ }^{71}$. Sin embargo, Núnez Delgadillo, en esta última parte de su obra, se decanta por la tradición de la emblemática (las centurias ${ }^{72}$ ), un género idóneo para la memoria, la predicación y el comentario de pasajes bíblicos ${ }^{73}$, y anuncia que ya tiene esas ideas expresadas y que serán publicadas prontamente en un tomo suyo, que quizás sea Minas celestiales, publicado al mismo año aunque, sin embargo, se considera anterior a Puerta de la luz.

\section{Conclusiones}

Puerta de la luz es una de las obras más curiosas escritas en lengua española durante la primera mitad del siglo XvII, puesto que recoge la herencia de la cabalística castellana, de la espiritualidad que los carmelitas habían renovado a lo largo del xvi y del lulismo que, a la sazón, estaba muy en boga tanto en Espańa como, sobre todo, en Europa. Se creía perdida, pero hemos podido localizar un ejemplar en la Biblioteca de las Descalzas Reales de Madrid, el cual nos sirve para conocer esta obra, que tan severo juicio mereció por parte de la Inquisición.

Después de la introducción al autor, teólogo, carmelita, predicador y profesor, hemos presentado una síntesis del contenido de Puerta de la luz (1629), mostrando sus influencias lulianas y cabalísticas, ambas vinculadas a la memorización de un contenido de significación teológica para usar en la meditación o en la construcción de sermones. Consta que Núnez Delgadillo enseñó lulismo en su labor de profesor de Teología y esa influencia la vemos en el uso de abecedarios, definiciones y combinaciones. Usó todas las letras del alfabeto, a las que atribuyó distintos significados según ocho abecedarios (dedicados a las perfecciones de Dios, de Cristo, de la Pasión de Cristo, del Santísimo Sacramento, de la Virgen María, de las virtudes del alma perfecta, de las ofrendas del alma a Dios y de las miserias que originan el pecado mortal). Los ejemplos suelen ser sencillos y se percibe la voluntad del autor

71. Véase F. Yates, "El lulismo como arte de la memoria», El arte de la memoria, Madrid, Siruela, 2005 [1966], pp. 197-220.

72. Un estudio específico es el de Mario Praz, Imágenes del Barroco. Estudios de emblemática, Madrid, Siruela, 2005. Véase también A. Bernat Vistarini y J. T. Cull, Enciclopedia Akal de Emblemas Españoles Ilustrados. Madrid, Akal, 1999.

73. En efecto, la obra Minas celestiales contiene algunas indicaciones para la predicación, siguiendo los esquemas del arte de la memoria. 
de escribir una obra accesible, aunque ello fue una de las causas de censura por parte de la Inquisición en 1630, que la acusaba de menosprecio de lo sagrado, ridiculización, artificiosidad y judaísmo. Lo cierto es que pretendía usar el alfabeto como instrumento de comprensión del mundo dando un valor evangélico a cada letra.

Hay que llamar la atención sobre la elaboración de la obra y la construcción de los abecedarios, que eran a la vez arte de la memoria e instrumento de predicación. El maestro Delgadillo mostró en ella su compromiso con el lulismo y con sus propias devociones, especialmente la mariología, presente en sus cursos universitarios. Estos ocho alfabetos pueden considerarse una de las fuentes más interesantes de la construcción de un arte de la memoria para predicadores en el Barroco hispano, a partir de elementos retóricos de la ciencia sagrada.

$\mathrm{Al}$ mismo tiempo, Delgadillo fue transgresor en el lenguaje, hasta el punto de ajustar sus alfabetos a la cotidianidad (lo que, en el caso de Cristo, levantó las sospechas de la Inquisición y fue uno de los motivos de su juicio negativo). Se trata una obra con finalidad religiosa, aunque el autor destaca que se puede aplicar también a las disciplinas profanas. Su construcción y sus ejemplos, así como el notable sabor judaico, tanto en el uso del lenguaje como en sus similitudes con la cábala, convierten esta obra en uno de los artificios más originales del Barroco, y en uno de los artes de la memoria más originales que existen, distinto a otros como el Fénix de Minerva, aunque no inferiores en audacia.

Pese a que el siglo Xvir en España dio algunos frutos literarios de gran singularidad, esta obra de Agustín Núñez Delgadillo, desconocida hasta hace pocos años, es un libro que debe ser estudiado por tratarse de una síntesis ingeniosa y atrevida, que mezcla el lenguaje popular y el religioso, el lulismo, la cábala y el arte de la memoria. Su construcción, así como su uso retórico y piadoso, merece la atención de los estudiosos del barroco hispano, pues puede considerarse una obra de referencia. Estas páginas han sido, así pues, una presentación detallada de la misma y de sus tesis principales, con la intención de darla a conocer e incardinarla en el marco de las corrientes culturales en las que fue escrita. 